\title{
THE EVOLUTION OF THE NATURAL DISASTER MANAGEMENT SYSTEM IN TAIWAN
}

\author{
Liang-Chung Chen, Jie-Ying Wu*, and Mei-Ju Lai
}

\begin{abstract}
Taiwan is vulnerable to many natural hazards that cause major economic losses. This paper examines the evolution of the natural disaster management system in Taiwan and finds that this system has progressed from an ad-hoc agency to a full government agency and the evolution had very strong relationship with the occurrence of mass disasters at that time. The first fundamental disaster management law-the Disaster Prevention \& Response Act (DPRA) was promulgated in 2000. It especially encourages the application of hazard mitigation technologies to reduce disaster losses. However, the operation of the disaster management system has continued to experience many problems in the past five years. Much still remains to be done to develop a mature disaster management system in Taiwan.
\end{abstract}

Key Words: natural disaster, disaster management system, Taiwan

\section{INTRODUCTION}

In the past 60 years, natural disasters have killed more than 9,000 people and destroyed more than 541, 000 buildings in Taiwan. These disasters also caused enormous economic losses. Earthquake, typhoon and flood are the three most significant natural hazards in Taiwan. Five major earthquakes happened in the past 60 years, and these five earthquakes killed more than 7,989 people and collapsed more than 60,000 buildings. There were about 3.44 typhoons per year (Wang, 1997). Data from Environmental Protection Administration in Taiwan (1995) shows that typhoons caused 2,497 deaths and destroyed 230,000 buildings during the period from 1961 to 1991 . Floods are usually caused by heavy rainfall in the summer season when typhoons come. The average economic looses caused by typhoons and floods were estimated to be about $0.68 \%$ of the GNP (Yen, 1997).

Hazard mitigation research has made tremendous progress recently in Taiwan. This paper tries to

*Corresponding author. (Tel: 886-3-3507001 ext. 3373; Fax: 886-3-3505441; Email: paulwu@ mcu.edu.tw)

L. C. Chen is with the Graduate Institute of Building and Planning, National Taiwan University, Taipei 106, Taiwan.

J. Y. Wu is with the Department of Urban Planning and Disaster Management, Ming-Chuan University, Taoyuan 333, Taiwan.

M. J. Lai is with the National Science \& Technology Center for Disaster Reduction (NCDR), Taipei 106, Taiwan. be a platform for researchers to discuss how to apply hazard mitigation technologies to the governmental disaster management system. Because some of the authors of this paper were involved in the formulation of the National Hazard Mitigation Program (NHMP) and Disaster Prevention and Response Act (DPRA), this paper can also be viewed as introspection on Taiwan's current disaster management system.

The method of this paper relies on literature review. These literature include central and local government ordinances, regulations and reports as well as some research papers. Due to the historical and political context that Taiwan was a Japanese colony and returned to Chinese control only after WWII, this paper only studies the time period after WWII. Moreover, this paper only focuses on the natural disaster management system, because the management system for technological disasters is traditionally different from the one for natural disasters.

\section{THE EVOLUTION OF NATURAL DISASTER MANAGEMENT SYSTEM}

Katz and Kahn (1978) suggested an ideal integrated system means a well-defined and clearly differentiated structure of components with mutually agreed upon roles interacting over time in a coordinated manner to achieve common goals. "Well-defined and clearly differentiated structure of components" refers to the 
organizations in the system and "mutually agreed upon roles interacting over time in a coordinated manner" means operation functions over a long period of time with different contexts (focus issues) at different times in the system. To apply Katz's and Kahn's opinion to the state mechanism in Taiwan, the ordinances and regulations promulgated by the state apparatus have to be discussed. Therefore, this study describes the natural disaster management system from four approaches: ordinances, organizations, operations, and focus issues. The development history of the natural disaster management system can be classified into four stages according to related enactments implemented at that time.

\section{A period without Any Official Disaster Manage- ment Related Ordinance (1945-1965)}

There were 19 years from the end of World War II to 1964 during which several typhoons, floods and earthquakes happened. Two major disasters are highlighted in the historical record. The 87 (August 7) Flood in 1959 caused serious damage in 13 counties in central and southern Taiwan. This flood killed more than one thousand people and destroyed more than 45,000 buildings. The losses were estimated to be about $1 / 10$ of the national GDP for that year (Tai, 2001). Another catastrophic disaster was the Paiho Earthquake, which measured 6.3 on the Richter scale, and struck the southern part of Taiwan on January 18, 1964. This earthquake killed 106 persons and caused about 27,000 buildings to collapse or be damaged (Cheng et al., 1999). There was no disaster management related ordinance during this period. This was because during the martial law era, military and police were the major responders during emergencies.

\section{The Standard Procedure for Natural Disaster Assistance (SPNDA) Period (1965-1994)}

This period was 30 years from 1965 to July 1994 . The 1964 Paiho Earthquake forced the government to think how to effectively and systematically implement response and recovery right after disasters (Chen, 2005). The Taiwan provincial government, therefore, promulgated the SPNDA in 1965 as a standard procedure to follow after disasters. SPNDA was revised four times during this period. Two special municipalities, Taipei and Kaoshiung City governments also developed similar procedures in 1975 and 1981. The major contribution of SPNDA was to establish a task force style Disaster Prevention \& Response Council (DPRC), the Police Department in the Taiwan provincial government was the major organization to take this responsibility. In this period, disaster management mainly emphasized search and rescue, social assistance, and started to pay attention to pre-disaster preparedness during the flood danger period in summer. The disaster responders still depended on the military and the police as well as some governmental social workers.

\section{The NHMP Period (1994-2000)}

This period was 6 years from August 1994 to June 2000. Many scholars had advised the government to institute a comprehensive disaster management mechanism since late 1980. But the government didn't make any change to the mechanism until the occurrences of the Northridge Earthquake in January and the China airline air crash in July 1994 (Chen, 1997). The Executive Yuan promulgated the NHMP in August 1994. NHMP required four levels task force style of DPRCs in normal conditions and Emergency Operation Centers (EOCs) in an emergency. The operation of NHMP required three plans to implement disaster management related policies. These plans were: Disaster Prevention and Response Basic Plan (DPRBP), the Disaster Prevention and Response Operational Plans (DPROPs), and the Local Disaster Prevention and Response Plans (LDPRPs). In this period, disaster management emphasized disaster response, early recovery and pre-disaster preparedness.

\section{The DPRA Period (2000-present)}

This period began when the DPRA was promulgated in 2000 and continues to the present. The bill for a Disaster Prevention and Response Act was in the legislative Yuan in the late 90s, but it was not passed until the massive casualties and financial losses caused by the Chi-Chi Earthquake in 1999 (Chen et al., 2000). This event, which was also called the 921 earthquake had a magnitude of 7.3 on the Richter scale, killed 2,417 people, and caused 11,305 injuries. The enormous losses forced the government to improve the disaster management mechanism which directly facilitated the birth of DPRA in 2000. The DPRA is the first disaster management related fundamental law in Taiwan, which integrates the management mechanisms for natural and technological disasters and covers all four phases of the disaster management cycle: mitigation, preparedness, response and recovery. Both SPNDA and NHMP were suspended after the DPRA was promulgated.

\section{CURRENT NATURAL DISASTER MANAGEMENT SYSTEM}

The current disaster management system is established based upon the DPRA which can be categorized into the following three sections. 


\section{Disaster Management Organizations and Their Functions}

The current disaster management system consists of three governmental levels. Every level of government is required to establish a DPRC. The DPRC is responsible for relevant disaster management policies and plans. Since the DPRC itself is a task force style organization, it doesn't take responsibility for policies implementation. The specific agency, Disaster Prevention \& Response Committees (DPRCM) under the DPRC, takes charge of overseeing and implementing disaster related policies and plans. During an emergency, each level of government is required to establish a disaster EOC.

The essence of the DPRA is a hazard-specific management approach. At the central government level, five duty ministries are designated to respond to one or more types of mass disasters and implement related affairs. Moreover, militia corps and armed forces as well as non-government organizations (NGOs) and community organizations are all involved in an integrated countermeasure system when a major disaster takes place.

\section{Disaster Management Plans}

Following the concepts of NHMP, the duty agencies are required by the DPRA to draw up three statutory disaster management plans. These three plans have to be periodically reviewed or revised every three to five years due to social and environmental changes. These plans include: DPRBP, which is drawn up by the Central DPRCM; DPROPs, which should be developed at the central government level by duty ministries and public utility companies; and LDPRPs, which should be developed at local government level. These plans must be based on the environmental characteristics, hazard vulnerability, and social and economic conditions within each local jurisdiction. The LDPRP is a comprehensive plan, which covers all four phases of disaster management.

\section{Operation System}

The operation of disaster management is not only based on the disaster management plans described above, but also many supporting ordinances, regulations, standard operation procedures (SOPs) and guidelines at different government levels. Since the essence of Taiwan's disaster management is a hazard-specific approach, the five duty ministries as well as local governments have to develop supporting ordinances and regulations based on their own DPROPs or LDPRPs. The SOPs and guidelines have to clarify the details of what needs to be done or planned in the four phases of disaster management.

Article 22 of the DPRA encourages the application of hazard mitigation technologies to reduce disaster losses. These technologies include the development of hazards analysis methods and tools; the establishment and application of meteorological, geological and hydrological related databases; the establishment of a mechanism for the improvements in building structure performance.

\section{ISSUES FACING NATURAL DISASTER MANAGEMENT TODAY}

It has been more than four years since the DPRA was promulgated in July 2000. In the past five years, many issues arose:

\section{The Disaster Prevention \& Response Commit- tee is not a Specific Agency}

Even though the Disaster Prevention \& Response Committee (DPRCM) was established as a specific agency in the central government level based on DPRA, it didn't have a full time staff. The current DPRCM staff members are part-time personnel from National Fire Administration under Ministry of Interior. Due to the staffs' background, current disaster management still focuses on hazard preparedness and response, with very little emphasis on mitigation and recovery. The local DPRCMs have the same problem as the central government. This phenomenon is very similar to the findings of Lindell et al. (1996) and Lindell and Perry (2001) that lacking full time staff support had significant impact on the effectiveness of the Local Emergency Planning committees in the US.

\section{DPROPs Become Plans on the Bookshelf}

Even though the five duty ministries have developed DPROPs, the planning process is very critical. The duty ministries themselves developed most of the DPROPs. The planning process doesn't involve other agencies, let alone community participation. Therefore, the DPROPs become reports on bookshelves. Many supporting agencies don't even know what their roles in the disaster management mechanism are. Lindell et al. (1996) and Lindell and Perry (2001) had similar findings on this issue in the US.

\section{Supporting Ordinances and Regulations Have not Been Developed Well}

As mentioned above, the operation of the disaster management system in Taiwan needs the development of supporting ordinances and regulations at different government levels. Yet very few have been 
Table 1 Evolution of the Taiwan natural disaster management system

\begin{tabular}{|c|c|c|c|c|}
\hline & 1945-1965 & 1965-1994 & 1994-2000 & 2000-present \\
\hline $\begin{array}{l}\text { Major } \\
\text { ordinances }\end{array}$ & N/A & SPNDA & NHMP & DPRA \\
\hline Organizations & $\begin{array}{l}\text { Mainly rely on } \\
\text { military and police }\end{array}$ & 1 level of DPRC & $\begin{array}{l}4 \text { levels of DPRCs, } \\
\text { EOC }\end{array}$ & $\begin{array}{l}3 \text { levels of DPRCMs, } \\
\text { duty ministries, NGOs }\end{array}$ \\
\hline Operations & $\begin{array}{l}\text { During the } \\
\text { emergency time. } \\
\text { No plan. }\end{array}$ & $\begin{array}{l}\text { During the } \\
\text { emergency or flood } \\
\text { protection period. } \\
\text { No Plan. }\end{array}$ & $\begin{array}{l}\text { Focus on the } \\
\text { emergency period and } \\
\text { a little on peace time. } \\
\text { DPRBP, DPROP, } \\
\text { LDPRPs }\end{array}$ & $\begin{array}{l}\text { Focus on both } \\
\text { emergency and } \\
\text { normal times. } \\
\text { DPRBP, DPROP, } \\
\text { LDPRPs, SOPs }\end{array}$ \\
\hline Focus issues & $\begin{array}{l}\text { Search and rescue, } \\
\text { social assistance }\end{array}$ & $\begin{array}{l}\text { Search and rescue, } \\
\text { social assistance, } \\
\text { flood preparedness }\end{array}$ & $\begin{array}{l}\text { Response, recovery } \\
\text { and preparedness }\end{array}$ & $\begin{array}{l}\text { Four phases of } \\
\text { disaster management }\end{array}$ \\
\hline
\end{tabular}

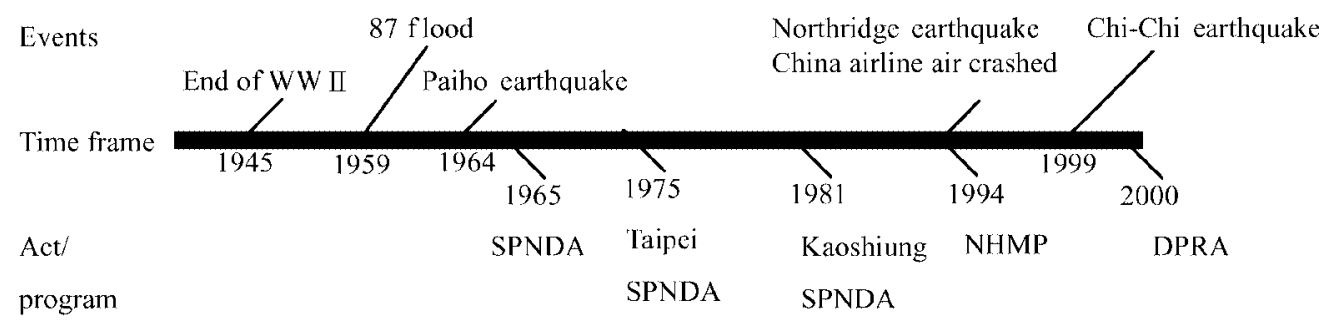

Fig. 1 Major disasters and the promulgations of related ordinances in time sequence

developed in the past four years. Most duty ministries thought such actions was the DPRCM's responsibility.

\section{The Coordination Mechanism Did Not Develop Well between the Central Government and Lo- cal Governments}

Taiwan is a highly centralized state. Traditionally, local governments didn't think they had the capacity for disaster management. Instead, they relied heavily on support from the central government. Moreover, since Taiwan is a small island, even a local disaster becomes a mass media headline. This sometimes has forced the central government to take responsibility for local disasters.

\section{Local Government Did Not Have Enough Bud- gets to Implement all Four Phases of Disaster Management}

As mentioned above, Taiwan is a highly centralized state, so few local governments even have enough tax income for their own staffs' salaries. Thus, local government relied heavily on budget support from the central government. Since local governments didn't have large enough budgets and mayors don't think the implementation of all four phases of disaster management a high enough priority to request funds from the central government, the local governments lacked the capacity to implement all four phases of disaster management.

\section{DISCUSSION AND CONCLUSIONS}

This study found that disaster management evolution in Taiwan evolved over six decades from the absence of related ordinance to a systematic status and this evolution had very strong relationship with the occurrence of mass disasters (see Fig. 1 for reference). These mass disasters not only included the 87 flood, Paiho earthquake, and the Chi-Chi earthquake, which happened on the island, but also the China Airline air crash in Japan and the Northridge earthquake in the US. The experience of the disaster management system evolution in Taiwan is consistent with Birkland's (1997) theory that disasters serve as "focusing events" that can be exploited to induce policy changes.

Over the past 60 years, Taiwan's disaster management system gradually involved more government organizations of different levels as well as NGOs, the operation of the system and the functions of responsible organizations were transformed from task force style to specific agencies (see Table 1 for reference). Moreover, the system has gradually progressed from search and rescue during emergencies and social 
assistance in the early recovery phase to a comprehensive disaster management system that covers the four phases of mitigation, preparedness, response and recovery.

The experience of the past five years shows the current system still focuses on emergency preparedness and responses even though the DPRA is designed as a comprehensive approach. This is probably because DPRCM doesn't have a full-time staff. The planning process of DPROP doesn't have much participation from other agencies or communities, which tends to make the DPROP a report on a bookshelf. Moreover, lacking supporting ordinances and regulations developed by the duty ministries as well as the local governments prevents the DPRA from reaching its goal. To resolve the problems described above, this study has the following recommendations.

\section{A Specific Agency, DPRCM, with Full Time Staff for Disaster Management is Necessary}

Lee (2005) and Chen (2005) suggested that DPRCM should be a specific agency with full time staff for both central and local governments. Because of budget limitations in both central and local governments, it is very difficult for the public sector to hire additional staff for the DPRCM. Therefore, adjusting manpower from other agencies in the same governmental body is the best way. The Taipei city DPRCM provides a good example. It is the only committee in Taiwan having full time staff. Most of its staff is from Department of Rapid Transit System (DRTS). DRTS had surplus manpower after completing many subway routes in Taipei area.

\section{To Involve More Agencies in the DPROPs Plan- ning Process will Enhance the Effectiveness of the DPRCM and Duty Ministries}

The greatest benefit of the DPROPs is not the written plans themselves but the planning process. Spangle Associates and Robert Olson Associate (1997) found that, although few local officials actually referred to the plan after the Northridge earthquake, the process of preparing the plan was very helpful. Many mentioned that they knew what their responsibilities were and what needed to be done after the quake because they had resolved these issues during the planning process.

\section{The Central DPRCM Should Explicitly Mandate the Development of Supporting Ordinances and Regulations by Local Governments as Well as Duty Ministries}

Since Taiwan follows the "Statute Law" system, lots of ordinances and regulations needs to be promulgated to normalize governmental operations. Therefore, the development of the disaster management related ordinances and regulations will enhance the operation of disaster management. In fact, the central DPRCM started to evaluate the performance of local disaster management from last year and one of the evaluation items is the preparedness of the supporting ordinances and regulations.

\section{The Establishment of Mandates Requiring Local Disaster Management is Necessary}

The US experience suggests that the mandated requirements will enhance the performance of the local emergency planning committee (May, 1993, May and Birkland, 1994). Since Taiwan is a centralized state, the establishment of the mandated requirements should be coupled with financial and technical assistance from the central government as well as professional groups. The central DPRCM and National Science and Technology Center for Disaster Reduction have started to promote universities as collaborative teams to co-operate with county government to enhance the local abilities of disaster management. The effects of these kinds of assistance need to be evaluated and the mandated requirements need to be set up clearly according to the local conditions.

\section{REFERENCES}

Birkland, T. A., 1997, After Disaster: Agenda Setting, Public Policy, and Focusing Event, Georgetown University Press, Washington D.C, USA.

Chen, C. S., 1997, "The Promotion and Implementation of Disaster Reduction in Taiwan," Proceedings of the National Conference on Disaster Reduction, Tainan, Taiwan, pp. 1-10.

Chen, L. C., 2005, 'The Development of the Disaster Management System in Taiwan," presented at the Chien Szu-liang memorial speech, Taipei, Taiwan.

Chen, L. C., Lee, W. W., and Lai, M. J., 2000, “A Formulation of Disaster Prevention and Response Act," NAPHM News Letter. Vol. 2. pp. 3-12.

Environmental Protection Administration, 1995, Environmental Information in Taiwan R.O.C., Environmental Protection Administration, Taipei, Taiwan.

Katz, D., and Kahn, R. L., 1978, The Social Psychology of Organization, Wiley, New York, USA.

Lee, M. L., 2005, The Command System and Response Strategies for Major Health Crisis, National Health Research Institutes, Taipei, Taiwan.

Lindell, M. K., and Perry, R. W., 2001,"Community Innovation in Hazardous Materials Management: Progress in Implementing SARS Title III in the 
United States," Journal of Hazardous Material, Vol. 88, pp. 169-194.

Lindell, M. K., Whitney, D. J., Futch, C. J., and Clause, C. S., 1996,'The Local Emergency Planning Committee: A Better Way to Coordinate Disaster Planning," The Disaster Management in the U.S. and Canada: The Politics, Policymaking, Administration and Analysis of Emergency Management, R. T. Silves and W. L. Waugh ed., Charles C. Thomas, Springfield, IL, USA.

May, P. J., 1993, "Mandate Design and Implementation: Enhancing Implementation Efforts and Shaping Regulatory Styles." Journal of Policy Analysis and Management, Vol. 12, pp. 634-663.

May P. J., and Birkland, T. A., 1994, "Earthquake Risk Reduction: An Examination of Local Regulatory Efforts," Environmental Management, Vol. 18, pp. 923-937.

Tai, P. T., 2001, The floods of 1959, Taiwan History
Association. Available: http://www.twhistory. org.tw/20010806.htm

Spangle Associates and Robert Olson Associates, 1997, The Recovery and Reconstruction Plan of the City of Los Angeles: Evaluation of Its Use after the Northridge Earthquake, Spangle Associates, Portola Valley, CA, USA.

Wang, J. T., 1997, "Climate hazards and prevention," Natural Hazards and Prevention in Taiwan, C. L. Yen, and C. H. Loh, ed., Ministry of Education, Taipei, Taiwan, pp2.1- 2.19.

Yen, C. L., 1997, "Introduction of natural hazards in Taiwan", Natural Hazards and Prevention in Taiwan, C. L. Yen, and C. H. Loh, ed., Ministry of Education, Taipei, Taiwan, pp1.1-1.13.

Manuscript Received: Apr. 28, 2005 Revision Received: Aug. 11, 2005 and Accepted: Sep. 26, 2005 